\title{
Factor Model of Labour Productivity in the Coal Mining Industry
}

\author{
Evgeniy Kharlampenkov ${ }^{1}$, Irina Kudryashova ${ }^{1,{ }^{*}}$, Natalia Zakharova ${ }^{2}$, and Anastasiya \\ Loginova $^{1}$ \\ ${ }^{1}$ Plekhanov Russian University of Economics, Kemerovo branch, 650992, 39, Kuznetskiy prospect, \\ Kemerovo, Russia \\ ${ }^{2}$ Plekhanov Russian University of Economics, 117997, 36, Stremyanny lane, Moscow, Russia
}

\begin{abstract}
In the article the problem of increasing labour productivity at Russian coal-mining enterprises is considered. The authors note the impossibility of intensive development of the coal industry, the formation and development of effective models of industrial enterprise management without a radical increase in labour productivity, which is an indicator of the level of efficiency of human labour costs in the production of the final product per unit time. On the example of coal enterprises in the Kemerovo region, the authors investigate the dynamics of coal production and the level of labour productivity depending on the method of production: underground or open. The authors justify the need to assess labour productivity on the basis of system analysis and using a multiplicative model. On the example of the Kuzbass coal industry, the authors investigated labour productivity in the context of assessment of influence of major factors such as the introduction of new equipment and mining technologies, the formation of qualified personnel, robotics basic processes of coal mining, introduction of system of quality management and information technologies, etc. Using a multiplicative model evaluation of the labour productivity it's obtained estimates of the influence of these factors on the change in the level of productivity. Thus, the article solves one of the actual problems of today's reality and has considerable theoretical and practical importance.
\end{abstract}

\section{Introduction}

At the current stage, in conditions of economy digitalization without the use of the main endto-end technologies such as big data, neurotechnologies and artificial intelligence, wireless communication technologies, virtual and augmented reality technologies, which are relevant drivers of economic development, it is impossible to form and develop effective management models by an industrial enterprise and further increase labour productivity [1].

In some researches authors investigating the problem of labour productivity noted that "the main factor determining the high level of labour productivity in the regions of the Russian Federation" is the high share of the extractive industries in the economy of the region

\footnotetext{
* Corresponding author: kudrina2007@,mail.ru
} 
[2-4]. That is why it is very important to study this issue for a coal mining region such as Kuzbass.

The long-term development program of the coal industry in Russia for the period up to 2030 poses great challenges to the enterprises of the industry, requiring innovative approaches in their solution and assuming that the extensive development of this industry goes back to the past, giving way to intensive transformation. The intensive development of the coal industry is based on several directions: use of new technology with elements of robotics; use of digital technologies in coal mining aimed at intensification of production processes; improvement of management level in terms of organization of production processes; increase of labour productivity including through restructuring of coal companies workers.

The purpose of this research is the labour productivity research in the coal industry on the basis of multiplicative (or factorial) model of its assessment on the example of the coal enterprises in Kuzbass.

This indicator, which in quantitative measurement characterizes the quantity of produced products by the worker for a certain period of time, in qualitative terms reflects the technological level of production [5].

The intensive use of labour resources in mines and coal strip mines of the region, which provides for reduction of costs per unit of production by using modern methods of labour organization and new equipment, contributes to increase of labour productivity, which is an indicator of the level of efficiency of human labour costs in production of the final product per unit of time. For the medium term the task of the Russian coal industry is set to increase labour productivity by 5 times.

\section{Materials and methods}

The methods of dialectical, systemic, logical, historical, comparative, statistical analysis and integrated approach were used in the realization of the goal. The authors used multiplicative model of labour productivity estimation based on factor analysis with application of estimation method of influence of dimension of initial data on resulting labour productivity index.

\section{Results and discussion}

In 2018, coal enterprises of the Kemerovo region produced 255.3 million tons of coal, at the same time an increase in annual production was 5.7\% compared to 2017 . The structure of coal production with the predominant share of open-process production has changed. There was a fundamental restructuring of traditional production methods -165.8 million tons of coal were produced in coal strip mines, 89.5 million tons of coal were produced in mines. Studies have shown that some form of mining significantly affects labour productivity, which varies from 11,954 t/year to 5,700 t/year in Kuzbass coal strip mines and from 8,130 t/year to $2,590 \mathrm{t} /$ year in the underground mining taking into account mining and geological conditions. World practice shows that labour productivity in open mining is higher than in underground mining, which is due to lower labour costs, easier and safer way of organizing labour processes. However, the introduction of new equipment in the underground mining method allows to increase production at mines. In 2018, more coal was produced underground mining in the Kemerovo region, 4.6 million tons or $7.3 \%$ more in the mines during the year than in 2017, most of the coking coal were also produced in the mines - 48.2 million tons of coal which exceeded the level of 2017 by $14.5 \%$. Labour productivity per coal mining worker was 334.1 tons ( +15.9 tons, growth by $5.0 \%$ compared to the previous year) 
in 2018, including 230.1 tons ( +28.1 tons, growth by $13.9 \%)$ in mines, and 413.2 tons $(+5.7$ tons, growth by $1.4 \%$, respectively) in coal strip mines.

The transition to automated, computerized and robotic coal mining technologies, including the introduction of "Smart Mine" and "Smart Coal strip mine" projects (otherwise called "Smart Coal Mining"), provided for by the development program of the coal industry in Russia, allows to move to progressive coal mining technologies, and therefore to increase labour productivity in the industry.

The main factors determining the level of labour productivity are the indicators of production and labour intensity. The output indicator is calculated as the ratio of output to labour costs and shows output per unit of labour costs. This indicator depends both on the technical equipment of the production process and on its organizational and information support. The indicator of labour intensity describes the ratio between labour costs and production volume and shows how much labour is spent on production of a unit of production.

A coal-mining enterprise is a rather complex system, comprising a large number of components, on the work of which both the overall result of the enterprise and the labour productivity of the individual worker depend. It is worth assessing labour productivity based on system analysis. To estimate the labour productivity of coal miners, we used a multiplicative model generally expressed by formula 1 :

$$
Y=\prod_{i=1}^{n} x_{i}=x_{1} \times x_{2} \ldots \times \ldots x_{n}
$$

where: $x_{i}-$ a factor influencing labour productivity;

$n$ - number of influence factors.

The use of the multiplicative model of labour productivity estimation is due to the fact that the productive indicator, in this case labour productivity, is a combination of several factors influencing coal production [6-8]. In order to identify the impact of various components on the labour productivity in the coal industry, a method of assessing the impact of the dimension of the source data on labour productivity - factor analysis - has been used in studies involving a number of variables.

Of particular note is the change in world and domestic coal prices, which indirectly affects labour productivity. If the increase in the capacity of enterprises in the Kuzbass coal industry amounted to 17.7 million tons in 2018, the projected indicator in 2019 is estimated by analysts at only 8.2 million tons, i.e. more than 2 times lower than the level of 2018 [9]. This is a signal of a decline in the investment attractiveness of the industry, with all the resulting consequences, if not a decrease in coal production itself, at least a decrease in its growth rate. It is worth noting that the dynamics of world coal prices in 2019 is characterized by a sharply downward trend: compared to the average values of 2018 , its fell by more than $10 \%$, in particular the cost of one ton of coal in the Asian market is \$90 against $\$ 103$ on average in the past year, and in Western and Eastern European markets, due to a radical decline in demand, the price of one ton almost halved to $\$ 51$, the average cost of a ton of hard coal at the end of 2019 was $\$ 70$ [9].

Analysis of the work of coal-mining enterprises in the Kemerovo region allowed to systematize a number of main criteria affecting labour productivity: the number of workers of industrial and industrial personnel; the level of mechanization of main production processes; the level of robotics of the mining process; level of organization of production processes in the enterprise, level of informatization of production processes; skill level of personnel. It is worth noting that a number of criteria are regulated, related to the introduction of innovative mining methods and labour organization with significant management impact, and a number - partially regulated, poorly dependent on the management model and business 
processes of the organization. For example, if the number of industrial and production personnel is a regulated parameter, as well as the level of skills of the personnel, the level of mechanization and robotics and the information support of production processes, the nature of the organization of production processes, the number of days of downtime per worker, the saving of working time through innovation; the change in the hourly output associated with the change in prices relative to the planned output and the change in the hourly output associated with the change in the production structure with respect to the planned output are partially regulated criteria. The most important unregulated parameter is the mining and geological conditions of bedding, which often literally determines the level of labour productivity.

According to the selected model, there is a need to assess the impact of the above factors on labour productivity. At the same time, the degree and nature of the influence of these factors on the final result will vary. An analysis of the labour productivity of miners from 2010 to 2015 showed a $25 \%$ increase in labour productivity, on average for the industry, mainly due to the release of personnel, when the share of workers in the coal industry decreased by $10 \%$ during this period, exacerbating the unemployment problem in the region. While in 1996 the average number of workers in the Kuzbass coal industry was 211.5 thousand miners, in 2019 it approached the mark of 90 thousand miners. Alternative jobs in new industries for the region, where released miners could continue their work activities, have not been created in the region during this period [10].

In the further period from 2016 to 2018, the trend of ahead of labour productivity growth strengthened, which is clearly seen in the example of ZAO "Shakhta Belovskaya", which is part of GC "Karakan-Invest". Labour productivity in this enterprise increased by $17 \%$ (from 626 tons/person to 735 tons/person) during these years, while the number of personnel increased by $14 \%$ (from 608 to 697 people) [11]. The relative factor of labour productivity growth, in this case the acceleration rate, is determined by formula 2 :

$$
X_{c h}=\frac{\Delta W(Q)}{\Delta W_{c h}}=\frac{735-626}{697-6}=1.22
$$

where: $\Delta \mathrm{W}(\mathrm{Q})$ - change of labour productivity of mine workers, $\mathrm{t} /$ person; $\Delta \mathrm{W}_{\mathrm{ch}}$ - change in number of workers, persons.

On average for the Russian coal industry this indicator is in the range of $1.17-1.24$. In many ways, the growth of this factor is due to the creation of high-productivity jobs, investments in their creation, introduction of new technologies, improvement of the skills level of personnel, increase of wages and improvement of working conditions. It is caused by the fact that in the company it is created highly professional engineering and engineering management team, at the same time $80 \%$ of workers have the higher education and most of miners has length of service in the company more than 5 years.

Mining at Kuzbass mines is carried out in a mechanized way with the use of modern mining complexes with partial robotics of the production process. This allowed, for example, SUEK JSC to increase underground production volumes by $49 \%$ in the period from $2014-$ 2018 , and labour productivity to increase by $90 \%$. In assessing the impact of this factor on labour productivity in the coal industry, the correlation coefficient of modern equipment has amounted to 0.54 over the last 5 years on the example of SUEK JSC, which indicates its decisive nature of impact, which determines the level of labour productivity.

Management of organizational and technological processes in enterprises in the industry is an important leverage opportunity on the level of labour productivity. Practically this element was laid down during the Stakhanov records, which allowed to dramatically increase labour productivity on the basis of division of labour, organization of production processes. This approach, based on quality management standards, is currently being actively used. The 
improvement of production management leads to a reduction in the number of administrative and managerial employees and workers, as well as auxiliary workers, which is a favourable factor. Development of work on automation of production process and optimization of resources necessary for its implementation in coal enterprises allows to reduce labour intensity of these works and release part of employees engaged in accounting operations, which leads to reduction of total number of personnel, not only not reducing, but even increasing the share of workers directly connected with production [12]. This is confirmed by the following facts: the average number of workers at coal mining enterprises in the Russian Federation in 2018 amounted to 146.9 thousand people $(+4.3$ thousand persons to the level of 2017, the increase was 3.1\%). According to the main activity, 142.0 thousand people worked in the production process at the enterprises of the industry $(+6.3$ thousand people, increase $-4.6 \%$ ). By category of employees, the average number of workers in enterprises of the industry was distributed as follows: employees of administrative and management personnel $-9,285$ people $(+193$ people, growth $-2.1 \%)$, engineering and technical workers $-21,199$ people $(+815$, growth $-4.0 \%)$, coal mining workers $-103,137$ $(+3,031$, increase $-3.0 \%)$. As can be seen from the above data, the introduction of modern coal mining equipment, automated process control systems for production control and planning, with the increase in the number of engineering and mining and mining bottoms workers engaged in coal mining, has increased labour productivity in open and underground development. In coal strip mines automated control systems of mining equipment operating in the mode of dispatcher adviser are increasingly being used. The use of such systems allows the dispatcher to make more reasonable decisions on the operation of mining transport equipment and provides an increase in the replaceable productivity of excavators by $5-7 \%$, which for these enterprises is a significant factor of growth and leads to tangible positive results.

The increase in labour productivity in the mining enterprise areas due to the introduction of a quality management system (QMS) in the enterprise can be determined by formula 3 [13]:

$$
\Delta P_{l}=\frac{1}{n} \sum_{i=1}^{n}\left(S_{i}-S_{0}\right)
$$

where: $S_{i}$ - labour productivity after QMS implementation;

$S_{0}$ - labour productivity before QMS implementation;

$n$ - number of plant site in the enterprise.

As the experience of domestic enterprises shows, the introduction of QMS can provide labour productivity growth by $24 \%$. This is achieved by strengthening control over performance of production tasks, prompt resolution of recurring problems, rapid response to emerging problems, their optimal structuring and constant training of personnel. Practice has shown that it is difficult to identify the effect or increase of labour productivity in a working coal enterprise through the introduction of QMS or "Lean Production System". Based on the analysis of the coal industry enterprises in the Kemerovo region, which have implemented the QMS, such as Raspadskaya Coal Company LLC, Kuzbassrazrazugol JSC, the relative factor of the influence of the QMS on labour productivity will accept 0.12 at the level of the average value in the Kemerovo region [14].

The informatization of production processes plays an important role in increasing productivity. Information technology is a set of clearly defined targeted actions of employees to process information for decision-making using computer equipment. Timely preparation of information, its transfer, data processing reduces non-production downtime of production sites. It should be noted that the problem of coal enterprises in the field of informatization is the introduction of an information system in the enterprise to support decision-making and 
production of digital products. Analysis of data on the main regions of coal mining in the Russian Federation - Kuzbass, Saha (Yakutia), Komi Republic - based on the share of innovative products in GRP showed that information and communication technologies used in the coal industry allow to increase labour productivity by $1.17 \%$ [10]. The relative value of the factor of influence on labour productivity from the use of information technologies is taken to be 0.02 .

Taking into account the assessment of factors affecting labour productivity in the coal industry and using the multiplier model and labour productivity statistics, it is possible to predict the dynamics of changes in labour productivity in the coal industry. Here, the multiplicative model is represented by formula 4 :

$$
Y=\left(\prod_{i=1}^{n} x_{i}\right) \times t_{j}+a
$$

where: $t_{i}$ - time period;

$a$ - special constant.

Data of labour productivity dependence are shown in Figure 1.

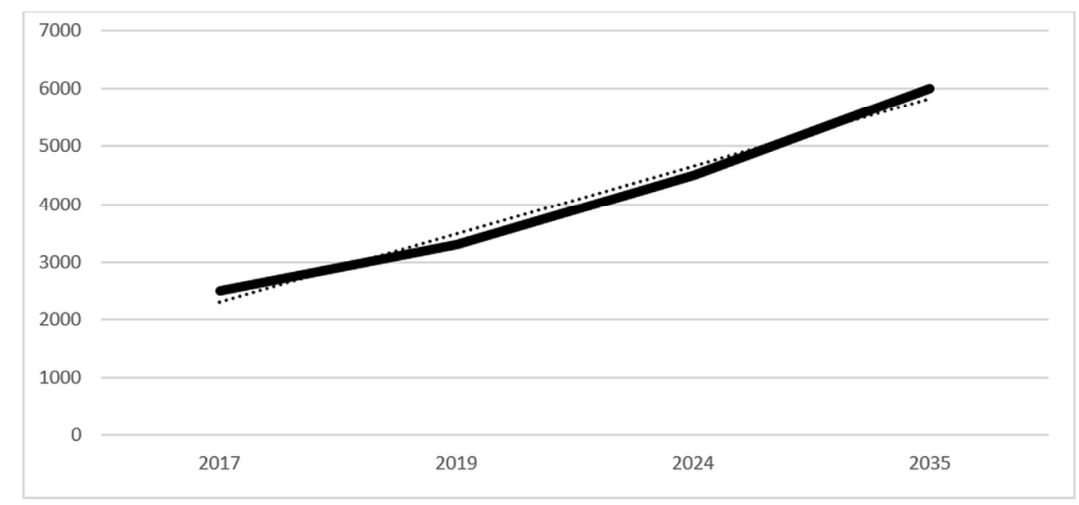

Fig. 1. Forecast of changes in labour productivity by years in the coal industry of Kuzbass, $t$ /person [15].

Taking into account the obtained results and evaluation of factors, we will determine the numerical value of each factor in the multiplicative model using the program "MatCad". Our research has shown that the absolute factor determining the introduction of new mining equipment and the number of personnel, its qualification, is the most important and has a numerical value in the presented model $-\mathrm{K}_{\text {пер }}=29.5$. The value of the factor determining the creation of highly intelligent jobs and their robotics $-K_{\text {poб }}=14.7$, but the absolute values of the factors determining the introduction of the QMS at the enterprise and informatization processes will be $\mathrm{K}_{\text {СмК }}=3.4$ and $\mathrm{K}_{\text {инф }}=0.79$ respectively. It is worth noting that the influence of these factors changes in the time interval, if you refer to the labour productivity analysis for the period 2010 - 2019, since 2013 the labour productivity of Kuzbass coal-mining enterprises has been increasing at a significantly higher rate than in the previous period, which is related to the rise in world energy prices, the introduction of new technologies, the active use of innovative management techniques and the digitalization of individual production processes in mines and coal strip mines. This can lead to the redistribution of numerical values of factors affecting labour productivity. The resulting multiplicative model linking labour productivity factors takes the following form (formula 5):

$$
Y=\left(K_{\text {pr }} \times K_{\text {rob }} \times K_{Q M S} \times K_{\text {inf }}\right) \cdot t+a=(29.5 \cdot 14.7 \cdot 3.4 \cdot 0.79) \cdot t+1150
$$


where: $\mathrm{K}_{\mathrm{pr}}-$ coefficient determining the influence of technical equipment and personnel professionalism;

$\mathrm{K}_{\mathrm{rob}}$ - coefficient determining the influence of the level of robotics in the mining process;

$\mathrm{K}_{\mathrm{QMS}}$ - coefficient determining the influence of QMS implementation in the enterprise;

$\mathrm{K}_{\text {inf }}-$ coefficient determining the influence of information support of process control at the enterprise.

The proposed model allows to make a forecast of the change of labour productivity in the coal industry based on the factors affecting its importance. It should be borne in mind that the development of the industry through the introduction of new coal mining technologies and production organization will lead to the fact that the values of factor coefficients may change, accordingly, the resulting model should be interpreted in this way: the larger the value of the new variable, the more important it becomes, the less the value of the new variable, the less important it is. At the same time factor analysis can be retrospective, which allows to identify reasons of growth of performance indicators for past periods, and perspective, which on the basis of behavior of factors allows to determine performance indicators in the future [16-18].

The question arises, and what are the prospects and main directions for increasing labour productivity in coal enterprises? In our view, several such areas can be identified:

- improvement of the skills level and education of miners, formation of professional teams of managers and line personnel, which is connected with the appearance of highly intelligent equipment at the mine;

- digitalization using modern computer technologies of production processes in the enterprise, allowing to make operational decisions and organize the work of mining bottoms; - intensive transition to the concept of "Lean Production", introduction of effective quality management systems;

- the transition from a traditional mine to an "intelligent mine", which allows real-time monitoring of the movement of workers at the mine, improving the safety level and avoiding losses due to unforeseen downtime due to insufficient organization of mining processes.

The proposed model allows to estimate changes in labour productivity in the medium term taking into account the change of factors affecting coal mining. At the same time, it is worth taking into account the fact, according to analysts, that the growth of railway tariffs by 2.5 times in the future until 2030, will allow to reimburse expenses of the coal enterprises at the level of prices for energy coal within \$95-100, and further growth of tariffs for transportation by 4 times will cause an increase in costs, which can be covered by the coal price not less than $\$ 120$ per ton. Modern events show that after three years of growth (from 2015 to 2018), the coal market is currently characterized by unfavourable price conditions. Fundamental factors of demand and supply, distortions of the market balance in one direction or another remain decisive for the energy and coking coal market. China, India and Japan remain major players in the Asian coal market, and coal consumption in these countries is based on policies to support its producers or import substitution (India). In Europe, thanks to the warm winter of 2018-2020, coal consumption also decreased due to the formation of reserves of the previous period. According to analysts, in the short and medium term in the period from 2020 to 2023 the unfavourable situation in the coal market will continue [9]. The adjusted Kuzbass development strategy, taking into account the current situation, envisages in the implementation of a favorable scenario to reach the production of 297 million tons of coal in 2035, and in the implementation of a pessimistic scenario to stop at the turn of 235 million tons. The situation with energy coal prices in 2019 was unfavourable and was, according to Rosterminalugl, \$55 per ton under the terms of FOB. For coking coals the situation is also not favorable, its cost in 2019 , on average, was $\$ 160-164$ per ton. It is worth noting that the change in coal consumption quickly affects its price, thus volatility is quite rapid. This situation may adversely affect the labour productivity of coal enterprises. 
And here it is possible to develop on two versions.

According to the first version, coal companies, while maintaining personnel potential, do not increase labour productivity in the short term, do not introduce new mining equipment, but do not increase wages of workers. The investments are directed to the organization processes and digitalization of the work in coal companies. In the second version there is a reduction of personnel, introduction of modern equipment, robotics of mining, which increases production per worker.

Accordingly, it is possible to include in the proposed model a factor that takes into account the effect on labour productivity of the elasticity of coal demand, then it will take the form of formula 6 :

$$
Y=K_{e l} \times\left(K_{p r} \times K_{\text {rob }} \times K_{Q M S} \times K_{\text {inf }}\right) \times t+a
$$

where: $K_{e l}$ - coefficient determining the influence of price elasticity on labour productivity.

The labour productivity growth in the coal industry is closely linked to coal prices in both external and domestic markets. A rather large share of Kuzbass coal is sent for export to the countries of South-East Asia from the port of Vostochny, where the largest coal terminal of Russia is located. The price of energy coal, depending on the brand, shipped in the port of Vostochny under the terms of FOB for the period from 2014 to the beginning of 2019, was between $\$ 75$ and $\$ 94$ per ton, by the end of the year decreased to $\$ 55-70$ [9]. The dynamics of changes in prices and labour productivity in the coal industry of the Russian Federation (on average for the industry) is shown in Figure 2.

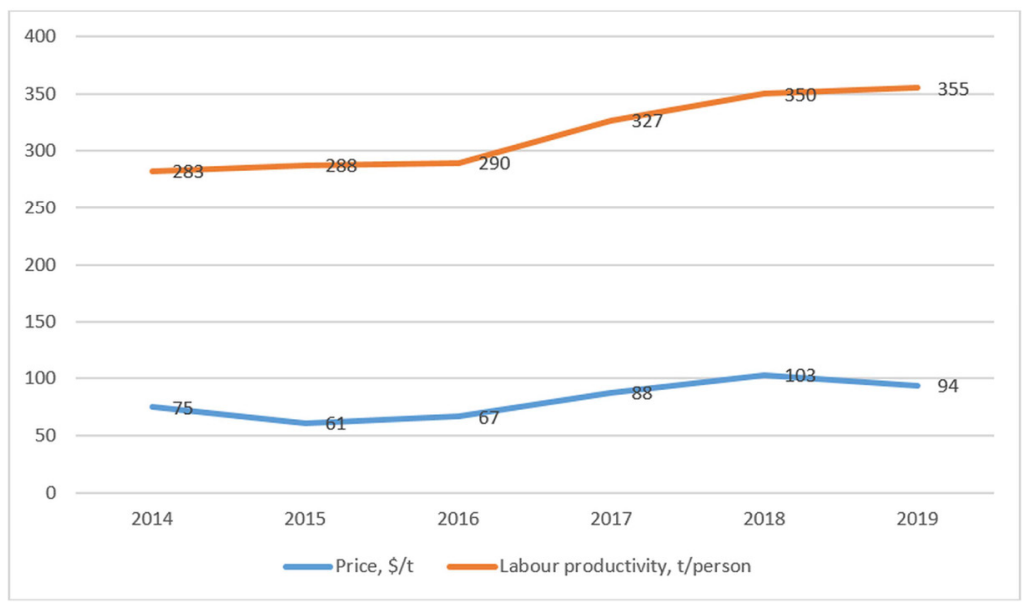

Fig. 2. Changes in energy coal prices according to terms of FOB $(\$ / t)$ and labour productivity ( $t /$ person) in the coal industry of the Russian Federation [9].

As can be seen from the figure, the statistical series of changes in coal prices and labour productivity in the industry are almost the same. The changes in the price of coking coal and labour productivity are shown in Figure 3. 


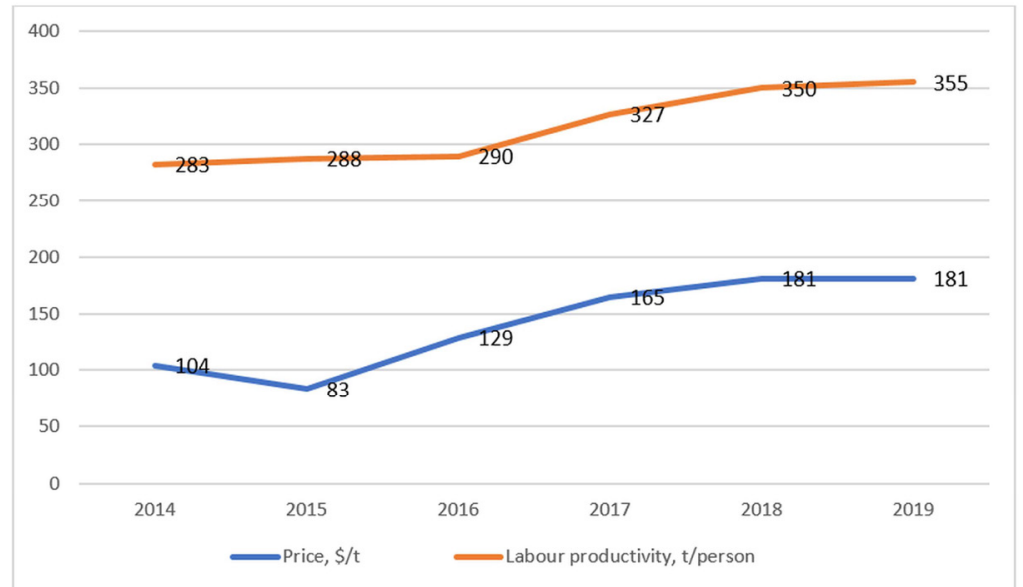

Fig. 3. Changes in coking coal prices according to conditions of FOB $(\$ / t)$ and labour productivity ( $t /$ person) in the coal industry of the Russian Federation [9].

Thus, based on the presented data, it is possible to conclude the practical identity of trends in the price of coking coal and labour productivity. The question arises: how does labour productivity elasticity change from changes in world coal prices and should labour productivity in the industry be adjusted depending on changes in product prices? In this case, the elasticity of labour productivity from price is presented as formula 7 :

$$
E=\frac{\Delta Q_{p r}}{\Delta P}=\frac{Q_{2}-Q_{1}}{Q_{1}}: \frac{P_{2}-P_{1}}{P_{1}}, \%
$$

where: $Q_{1}$ - labour productivity in the previous period, t/person;

$Q_{2}$ - labour productivity in the following period, t/person;

$P_{1}$ - price of previous period, $\$ / \mathrm{t}$;

$P_{2}-$ price of subsequent period, $\$ /$ t.

Differential indicators of elasticity for the period from 2014 to 2019 are given in Table 1.

Table 1. Differential indicators of labour productivity elasticity depending on the coal price [19].

\begin{tabular}{|c|c|c|c|c|c|c|}
\hline \multirow{2}{*}{$\begin{array}{l}\text { Coal rank, } \\
\text { indicators }\end{array}$} & \multicolumn{6}{|c|}{ Years } \\
\hline & 2014 & 2015 & 2016 & 2017 & 2018 & 2019 \\
\hline \multicolumn{7}{|l|}{ Energy coal } \\
\hline $\begin{array}{l}\text { Labour productivity, } \\
\text { t/person, } Q\end{array}$ & 283 & 288 & 290 & 327 & 350 & 355 \\
\hline Price, $\$ / t, \mathrm{P}$ & 75 & 61 & 67 & 88 & 103 & 70 \\
\hline $\begin{array}{l}\text { Elasticity of labour } \\
\text { productivity, E }\end{array}$ & - & -0.091 & 0.07 & 0.405 & 0.41 & -0.045 \\
\hline \multicolumn{7}{|l|}{ Coking coal } \\
\hline $\begin{array}{l}\text { Labour productivity, } \\
\text { t/person, } Q\end{array}$ & 283 & 288 & 290 & 327 & 350 & 355 \\
\hline Price, $\$ / t, \mathrm{P}$ & 104 & 83 & 129 & 165 & 181 & 164 \\
\hline $\begin{array}{l}\text { Elasticity of labour } \\
\text { productivity, E }\end{array}$ & - & -0.09 & 0.013 & 0.46 & 0.73 & -0.154 \\
\hline
\end{tabular}

As can be seen from Table 1, the coefficient of labour productivity elasticity depending on the price has different indicators, while labour productivity elasticity is less than 1 , that is, it is difficult to identify a clear pattern of change in productivity from the price. First of 
all, this is due to the fact that the change in coal prices is largely dependent on the development of the situation in the metallurgical and energy markets, the change in the demand in the market of materials, the production of which uses coking coal and, accordingly, thermal energy resources. However, by analyzing the change in the labour productivity elasticity, it can be concluded that the increase in coal prices leads to an increase in this coefficient and, therefore, coal companies pursue a policy of increasing labour productivity through the introduction of new equipment, innovative production methods and improving production organization. This trend is more pronounced in enterprises producing coking coal.

Unfortunately, analysts predict a decline in the price of coking and energy coal until 2023, which they believe will be sold at a price of $\$ 148-149$ per ton and \$78-79 per ton respectively [9]. On this basis, the question arises, and how labour productivity will change in a given period. In our view, two versions are possible. In the first versions, given that the introduction of new equipment and technological re-equipment is part of long-term enterprise development plans and will contribute to labour productivity growth, this growth will slow down, as coal production will not increase due to the stabilization of demand. At the same time, world prices will traditionally be influenced by the prices of coking coal, coke and steel in China 's domestic market, which is the largest importer and exporter in the world. The situation with COVID-19, despite being a medical problem, can significantly collapse the coal market. The decline in production due to the pandemic significantly reduces coal consumption in both the energy sector (analysts predict a 73 billion $\mathrm{kWh}$ decline in electricity consumption in China alone in 2020) and coking coal used in steel production. In the forecast period until 2024, the price of coking coal will vary from $\$ 130$ to 170 per ton [9]. But in the forecast period "surge" of deliveries to the countries of the Eurasian Union, Germany, Poland and the Baltics is expected, which will allow to maintain positive growth rate of labour productivity in the future.

The second version relates to the economic policy of the coal industry. In particular, the Strategy of Social and Economic Development of the Kemerovo Region for the period up to 2035 provides for a reduction in the number of workers employed in the coal industry. In this case, enterprises, based on the use of innovative methods of mining, introduction of new technology, transition to the concept of "intelligent mine (coal strip mine)" will introduce labour productivity programs in the industry combined with support for labour productivity growth at the federal level, when coal industry development programs estimate the forecast of coal production in the country to be an upward trend (by 2035 forecast at 480 million tons) [20].

Thus, on the example of the Kuzbass coal industry, the authors tried to study labour productivity in terms of assessing the influence of the main factors, such as the introduction of new technologies and technologies of coal mining, the formation of qualified personnel, robotics of the main processes of coal mining, the introduction of a quality management system and information technologies, etc. Using multiplicative model of labour productivity estimation, predicted estimates of influence of these factors on change of labour productivity level are obtained.

The qualitative increase in labour productivity of coal mining enterprises of the Russian Federation and Kuzbass in the future is based on the application of innovations that can fundamentally change the coal industry and bring it to a new level of high competitiveness and efficiency. But it is worth noting that with the increase in labour productivity there is also a negative side related to the release of workers of enterprises and the increase in unemployment. Taking into account the specifics of the single-industry city in Kuzbass, there is a problem of lack of free jobs where former miners could exercise their competences, as well as the need to retrain dismissed personnel for new professions. In order to solve these complex issues, in our view, it is necessary to take into account the experience of the UK in 
restructuring the coal industry, "which has transformed the North-East of England, where most mines were concentrated, into an industrial desert and an economically loss-making region" and the recent experience of restructuring the Russian coal industry in order not to repeat the mistakes of the past [20-21].

\section{Conclusions}

The article is devoted to the study of the problem of increasing labour productivity in coal enterprises of the Russian Federation. On the example of Kuzbass, factors affecting labour productivity in the coal industry are considered, which include introduction of new technologies and technologies of coal mining, formation of qualified personnel, robotics of the main processes of coal mining, introduction of quality management system and information technologies, etc. Using the multiplicative model of estimation of key factors of labour productivity in the coal industry the forecast of its dynamics till 2035 has been made.

From the point of view of the authors in the situation of deterioration of the world situation in the coal market it is possible to maintain a positive rate of labour productivity growth in the future by optimizing supplies, on the one hand, and state support for restructuring of the Russian coal industry, on the other hand.

\section{References}

1. I. Kudryashova, M. Venger, N. Zakharova, E3S Web Conf., 105, 02005 (2019)

2. A. Bufetova, World of economics and management, 17:4, 42-157 (2017)

3. N. Miheeva, Region: Economics and Sociology, 2, 86-112 (2015)

4. Yu. Alekseev, New science: strategies and vectors of development, 1:3, 175-177 (2017)

5. S. Voronin, V. Pestov, V. Trojnina, Econominfo, 1-2, 28-31 (2017)

6. E. Kuchina, A. Tashhev, Bulletin of SUSU. Economics and Management, 11:2, 42-47 (2017)

7. G. Trushina, News of the Higher Institutions. Mining Journal, 1, 95-102 (2019)

8. M. Egorova, P. Mar'in, Young scientist, 11.4:91.4, 95-98 (2015)

9. M.A. Pett, N.R. Lackey, John J. Sullivan, Making sense of factor analysis: The use of factor analysis for instrument development in health care research (Sage Publications, Thousand Oaks, 2003)

10. G. Krasnyanskiy, M. Revazov, The current state of the coal industry and prospects for innovative development (Mining Book,. Moscow: 2010)

11. L. Plakitkina, Mining Industry Journal, 3, 16-21 (2015)

12. V. Orehov, Anti-crisis model of Russian economy growth based on labour productivity improvement (INFRA-M, Moscow, 2018)

13. A. Ponomarev, Coal of Kuzbass, 5 (2018)

14. R. Karenov, G. Karenova, Problems of cost management at mining enterprises of Kazakhstan (CPI "Professional Education", Karaganda, 2007)

15. V. Senkus, MIAB, 4, 43-48 (2009)

16. E. Kharlampenkov, I. Kudryashova, Issues of Social - Economic Development of Siberia, 1:35, 90-95 (2019)

17. D. Maev, N. Grashchenkova, Bulletin of Udmurt University. Series Economics and Law, 27:5, 39-47 (2017) 
18. Sh. Magomedgadzhiev, Regional problems of transforming the economy, 4 (2009)

19. Dynamics and forecast of world coal prices. URL: https://ugmk.com/analytics/surveys_major_markets/coal/

20. I. Tarazanov, Russian coal journal, 3:1116, 64-79 (2019)

21. G. Belyakova, N. Faskevich, A. Dulesov, Issues of Social - Economic Development of Siberia, 4:34, 17-20 (2018) 